\title{
Polar cap convection patterns inferred from EISCAT observations
}

\author{
C. Peymirat, D. Fontaine \\ CETP-CNRS-UVSQ, 10-12 Avenue de l'Europe, 78140 Velizy, France
}

Received: 13 May 1996 / Revised: 25 November 1996 / Accepted: 26 November 1996

\begin{abstract}
From data of the European incoherent scatter radar EISCAT, and mainly from its tristatic capabilities, statistical models of steady convection in the auroral ionosphere were achieved for various levels of magnetic activity. We propose here to consistently extend these models to the polar cap, by avoiding the use of a predefined convection pattern. Basically, we solve the second-order differential equation governing the polar cap convection potential with the boundary conditions provided by these models. The results display the classical twin-vortex convection pattern, with the cell centres around 17 MLT for the evening cell and largely shifted towards midnight (3-3.5 MLT) for the morning cell, both slightly moving equatorward with activity. For moderate magnetic activities, the convection flow appears approximately oriented along the meridian from 10:00 MLT to 22:00 MLT, while in more active situations, it enters the polar cap at prenoon times following the antisunward direction, and then turns to exit around 21:00 MLT. Finally, from these polar cap patterns combined with the auroral statistical models, we build analytical models of the auroral and polar convection expected in steady magnetic conditions.
\end{abstract}

\section{Introduction}

During the last decade, several empirical models of the high-latitude ionospheric convection have been performed from various instruments: ground-based magnetometers (see Papitashvili et al., 1994 and references therein), radars (Foster et al., 1986a, b; Holt et al., 1987; Foster et al., 1989; Senior et al., 1990; de la Beaujardière et al., 1991; and references therein), spacecraft (Heppner and Maynard, 1987; Rich and Hairston, 1994; and references therein), and also a combination of all these

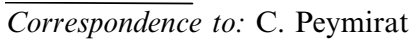

observations in the AMIE procedure (Richmond and Kamide, 1988; Lu et al., 1994, and references therein). On the whole, these studies contributed to display a dominant two-cell convection pattern, closing the antisunward drift within the polar cap by a return sunward flow at lower latitudes through the morning and evening sectors. The variability, observed in the global flow pattern and in the cell location and size, has demonstrated their dependence on number of controlling factors such as the season, the magnetic activity, the components $B z$ and $B y$ of the interplanetary magnetic field (IMF)... Evidence was given of the rapid response of the convection patterns to disturbed magnetic conditions, substorms, changes of the IMF, as illustrated for example in the instantaneous planetary maps derived from the AMIE procedure.

However, several aspects of the convection system are not presently fully understood. One of them, the structure of polar cap convection, has become an increasing interest due to its implications for our knowledge of the terrestrial environment. For instance, satellite observations of unexpected sunward convection deep inside the polar cap during northward IMF (Burke et al., 1979, and subsequent papers) have fed controversial interpretations, suggesting the distortion of the two existing cells, or the presence of extra polar cells, or the transient signature of rapid changes in the IMF. Although crucial, we do not approach this topic here, largely discussed in the literature over recent years (see Hill, 1994, and references therein).

The understanding of transient or localized events, and the proper identification of their own effects, require knowledge of the steady states from which they can develop. As a step towards further studies of these events, presently beyond the scope of this study, our major aim is to investigate from observations the influence of the auroral electrodynamics, closely coupled to magnetospheric processes, on the large-scale convection within the polar cap. This topic has already been approached using measurements of the Millstone Hill radar over the latitudinal range from $56^{\circ}$ to $73^{\circ}$. 
Statistics on the velocity data were performed to build average patterns of the convection electrostatic potential as a function of the magnetic activity index $K p$ and the IMF $B z$ and $B y$ components (Holt et al., 1987). Only partly accessible within the radar field of view, the auroral equipotentials were connected across the polar cap above $73^{\circ}$ invariant latitude by assuming a two-cell pattern with an asymmetry across the polar cap (Foster et al., 1986a), or by solving the Laplace's equation governing the convection potential with the neglect of field-aligned currents poleward of the radar field of view (Foster et al., 1986b). For the different purpose of deriving instantaneous convection maps from localized observations, the procedure AMIE (Richmond and Kamide, 1988) also relies on this statistical model to start the fitting process in data-sparse regions. Its role in the resulting pattern depends on the observation coverage and locations.

Following a similar guideline, we first take advantage of the tristatic capability of the European incoherent scatter radar (EISCAT) UHF to measure directly the three components of the convection velocities: this cancels out assumptions required by monostatic facilities and improves the error bars. Then, the simultaneous measurements of velocity vectors and of scalar parameter profiles give access to the ionospheric electrodynamics. From the same EISCAT data base of experiments of elevation scanning in the meridian plane (see Senior et al., 1990 for details), statistics and empirical models were performed for convection (Senior et al., 1990), conductances (Senior, 1991), and currents (Fontaine and Peymirat, 1996). They give a consistent description of the auroral electrodynamics over more than $10^{\circ}$ latitude and for different magnetic activity levels: quiet $\left(0<K_{p}<2\right)$, moderate $\left(2<K_{p}<4\right)$ and disturbed $\left(4<K_{p}<6\right)$. Due to its close coupling with the magnetosphere, the auroral ionosphere is a region of enhanced electric fields, currents, and conductances, which influence the convection at the planetary scale. In particular, the consistent statistical set mentioned contains pieces of information important to solve the convection potential equation within the polar cap. As with the auroral statistics, the computed polar cap potential will depend on the $K p$ index. Its use rather than IMF or other indices might be controversial, because the polar cap convection also depends on solar wind parameters, particularly at short time scales. However, we note that the computation method used in this work is independent of any index. It would apply in the same way with any large-scale distributions of auroral electric fields, currents, and conductances, and, similarly, the reliability of the results would be improved if a set of parameters, simultaneously observed or consistently modelled, is made available.

The method to compute the polar cap potential, based on the finite element technique, is briefly described in Sect. 2. It requires boundary conditions and also the knowledge of conductance and field-aligned current distributions within the polar cap, which are generally inferred from models. As indicated in Sect. 3 and 4, the number of assumptions can be substantially reduced, in particular from the use of the statistical set inferred from EISCAT. Finally, we present and discuss in Sect. 5 the polar cap convection patterns, computed to extend the statistical models of Senior et al. (1990).

\section{Method}

At the steady state, the convection electric field is assumed to derive from an electrostatic potential $\phi$, which is computed from the distributions of the ionospheric conductances $\Sigma$ and the field-aligned currents $j_{l /}$, by solving the equation of the current closure, height-integrated over the ionospheric layer:

$\operatorname{div}(\underline{\Sigma} \operatorname{grad} \phi)=-j_{/ /} \sin I$

where $I$ is the inclination of the magnetic field, $\underline{\Sigma}$ the conductance tensor, and $j_{/ /}$is positive for currents flowing into the ionosphere (downward).

We solve this second order differential equation over the polar cap by the finite element method with two boundary conditions, in a similar way to Peymirat and Fontaine (1994). More precisely, the domain covers all local times, and the latitudes between two circular boundaries at a constant invariant latitude. A poleward boundary is required to avoid the singularity at the pole in the mesh of triangular finite elements: it is taken as a small circle $\Gamma_{p o l}$ at $89^{\circ}$ invariant latitude. At $\Gamma_{p o l}$, the boundary condition is a Neumann condition, which expresses the preservation of the ionospheric horizontal currents. As the field-aligned currents are generally assumed to be negligible near the pole, this condition can be written as:

$\underset{\Gamma_{p o l}}{\oint} J_{\theta} \mathrm{d} \Gamma_{p o l}=0$

where $J_{\theta}$ is the meridional component of the ionospheric horizontal currents. The potential along $\Gamma_{p o l}$ is only assumed to be a constant. Its value, at first unknown, is a result of the computations. The equatorward boundary $\Gamma_{e q}$ is set at $70^{\circ}$ invariant latitude, and the conditions along $\Gamma_{e q}$ are Dirichlet conditions, where the potential takes the value predicted by the statistical models of the convection potential inferred from EISCAT data (Senior et al., 1990). Finally, to solve the elliptic equation of the polar cap potential, we performed a variational formulation which directly includes these boundary conditions: it ensures the uniqueness of the computed solution and has the advantage to satisfy rigorously the boundary conditions (see Peymirat and Fontaine, 1994, for details on the method).

The solution of Eq. (1) requires the additional knowledge of the polar cap conductances $\underline{\Sigma}$ and fieldaligned currents $j_{/ /}$. They are generally derived from models, and in the considered cases, their influence can be substantially limited, as indicated later. 


\section{Model of ionospheric conductances}

In the polar ionosphere, the conductances mainly depend on the solar illumination. From the data base mentioned already, Senior (1991) performed statistical models of the sun-induced contribution at the latitude of EISCAT, as a function of the solar zenithal angle $\chi$. We apply the same expressions at polar latitudes:

$$
\begin{aligned}
& \Sigma_{P}^{\text {Sun }}=1.81+8.88 \cos \chi \\
& \Sigma_{H}^{\text {Sun }}=21.58-0.21 \chi
\end{aligned}
$$

where the subscripts $P$ and $H$ refer to the Pedersen and Hall conductances.

Negligible at polarmost latitudes, the effects of precipitations progressively increase towards auroral latitudes, where the nightside belt of enhanced conductances dominates the global distribution. They add to solar conductances a contribution, dependent on latitude and local time, which should be taken into account. We make use of the model of Hardy et al. (1987) derived from precipitating electron fluxes measured on board the DMSP satellites for corrected geomagnetic latitudes higher than $50^{\circ}$. Apart from minor discrepancies, the resulting contribution $\Sigma_{P(H)}^{P r e}$ due to precipitations was found consistent with EISCAT observations for the three considered $K p$ ranges $0<K p<2,2<K p<4$, and $4<K p<6$ (Senior, 1991). Finally, the total conductances are expressed as:

$\Sigma_{P(H)}=\sqrt{\left(\Sigma_{P(H)}^{\operatorname{Sun}}\right)^{2}+\left(\Sigma_{P(H)}^{P r e}\right)^{2}}$

For example, Fig. 1a,b displays the isocontours of the Hall conductances for two ranges of $K p$, respectively $2<K p<4$ and $4<K p<6$, on polar maps with decreasing invariant latitudes from the magnetic pole at the centre down to $60^{\circ}$, and the magnetic local time indicated around the larger circle. The terminator is chosen along the line 06:00-18:00 MLT. The slow decrease from day to night of the sun-induced conductances in the polar cap is modified by auroral precipitations, which tend to intensify and to expand equatorward with magnetic activity.

\section{Model of field-aligned currents}

From the same EISCAT data base, Fontaine and Peymirat (1996) also derived statistical models of fieldaligned current densities in the auroral zone (between $62^{\circ}$ and $71^{\circ}$ invariant latitudes). They exhibit global features and densities consistent with the typical distributions deduced by Iijima and Potemra (1976a, 1976b, 1978) from the TRIAD satellite. However, the finite latitudinal coverage of EISCAT observations does not give access to the entire current pattern. In particular, the high-latitude dayside current system remains poleward of the field of view. Region 2 can be identified at almost all local times for each $K p$ range. The region 1 sheet widely intrudes on the nightside into a large
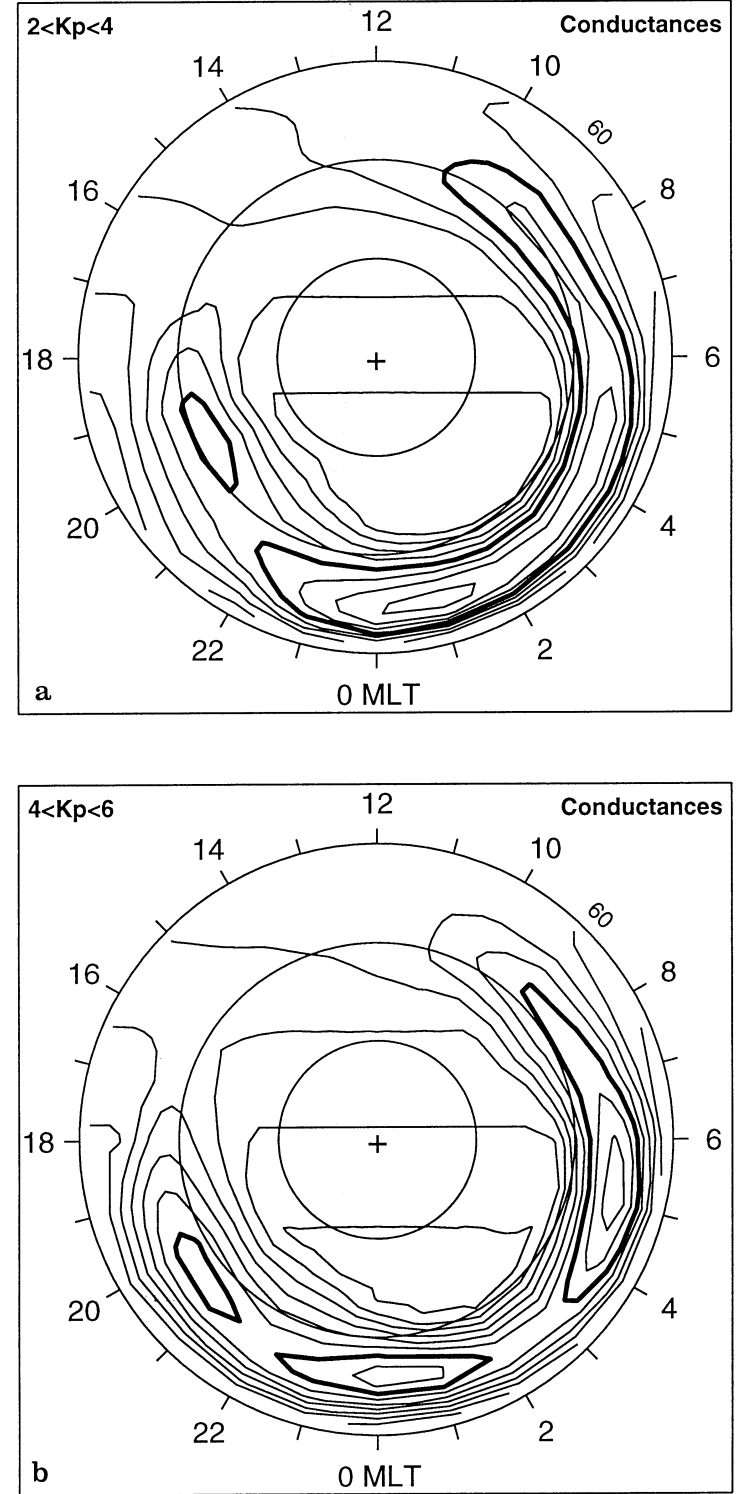

Fig. 1a,b. Isocontours of Hall conductances represented in polar maps between the north pole and $60^{\circ}$ invariant latitude, with the MLT indicated on the external circle. The contour interval is 2 mhos and the bold line corresponds a to 10 mhos for $2<K p<4$ and b to 13 mhos for $4<K p<6$

poleward half of the field of view for disturbed situations $(4<K p<6)$, it contracts somewhat poleward but can still be partly probed for moderate magnetic activities $(2<K p<4)$, while it almost disappears from the radar field of view for weak activities $(0<K p<2)$. This last case will be ignored in the following. For the two other cases, the total current intensity indicates that EISCAT is actually observing the major part of the field-aligned current system (signature of coupling processes between the ionosphere and the magnetosphere) which partly controls the polar cap convection. The problem consists in extending these current statistical models at somewhat more polar latitudes inaccessible to the radar range, in order to provide a consistent description of the global system. 
From Millstone Hill observations, Foster et al. (1989) achieved field-aligned current patterns at auroral and polar latitudes for various levels of auroral precipitation. Poleward of the radar field of view (i.e. above $73^{\circ}$ invariant latitude), the derivation of field-aligned currents already involves a poleward extrapolation of statistical electric fields observed at lower latitudes. The use of a pre-defined distribution of polar electric fields must definitely be avoided in the present work, which precisely aims at deriving them independently. Fujii and Iijima (1987) focused upon the relationships between the ionospheric conductances and the fieldaligned currents, but for very weak magnetic activities $(K p<1)$ which we do not consider here. From observations on board the satellites TRIAD (Iijima and Potemra, 1976a; 1978) and ISIS 2 (McDiarmid et al., 1979), Rich and Kamide (1983) proposed a simple analytical representation of field-aligned current patterns, which appears well suited to extrapolate the poleward current part unavailable from EISCAT. Firstly, it gives comparable patterns at the auroral latitudes probed by EISCAT. Secondly, it depends on two fitting parameters: $F$, the normalization factor for current densities, and $\mathrm{R} 21$, the ratio between the maximum densities of the region 2 and 1 , which both can be set to match EISCAT results. Indeed, this model exists with four versions. Identical in the night sector and also in the equatorward part, they mainly differ for region 1 and for the high-latitude dayside current system, depending on the sign of IMF $B y$ and on assumptions on their configuration:

1. If the auroral field-aligned current sheets are assumed to approach noon without overlapping, a small region of cusp currents is expected poleward of the auroral sheets on the afternoon side of the noon meridian for IMF $B y<0$ (case 1) or on the morning side for IMF $B y>0$ (case 2).

2. In the two other cases, the auroral sheets are assumed to overlap at noon: the morning region 1 sheet is expected to intrude into the postnoon sector poleward of the afternoon region 1 sheet for IMF $B y<0$ (case 3), or vice-versa, it is the afternoon region 1 sheet which intrudes into the prenoon sector poleward of the morning sheet for IMF $B y>0$ (case 4).

The field-aligned current models inferred from EISCAT, keyed to the $K p$ index, probably include a mixture of periods with IMF $B y<0$ or $>0$. However, for each $K p$ range, we could determine one single version of Rich and Kamide's (1983) models and the corresponding fit parameters, which match them at best and minimize the differences with the currents inferred from EISCAT data. We proceeded in the following way.

For $2<K p<4$, the entire region 2 is observed within a large part of EISCAT field of view, but only part of region 1 at the poleward latitudes of the nightside. In particular, it is not absolutely certain that EISCAT observes the peaks of the region 1 current sheets. The normalization factor, to apply to Rich and Kamide's (1983) model for fitting EISCAT current densities, is computed from region 2 maximum densities.
The parameter $\mathrm{R} 21$, ratio of the peak current densities between region 2 and 1 , is set to 0.5 , following Iijima and Potemra (1978). Then, from tests against the various versions, the best agreement with EISCAT results is met by case 3 of Rich and Kamide (1983) shifted northward by $1^{\circ}$ invariant latitude.

For $4<K p<6$, in addition to region 2, EISCAT also observes region 1 , which widely intrudes into the field of view at most local times, except maybe in the early afternoon. At least over the whole nightside, a zone of maximum densities is identified for both evening and morning sheets of both current regions. These maximum zones are used to normalize the model of Rich and Kamide (1983) and to estimate the parameter $\mathrm{R} 21$. We obtained 0.4 , by comparison with 0.6 predicted by Iijima and Potemra (1978). Since we cannot exclude the possibility of even larger region 1 densities at more poleward location in the morning or afternoon sectors, we finally set R 21 to 0.5 , the average between both estimates. The best fit to EISCAT observations is obtained hereby with case 4 of Rich and Kamide (1983).

Finally, and this is a first result, for both considered magnetic activity levels, EISCAT observations at auroral latitudes cannot be fitted by patterns like case 1 and 2 of Rich and Kamide (1983), which assume a separation without any overlap of the current sheets at noon. Secondly, we note that the observed current distribution on the dayside is better fitted by case 3 corresponding to IMF $B y<0$ for moderate activity, and by case 4 corresponding to IMF $B y>0$ for more active periods. This latter result indicates a global trend in our data set rather than a general relationship between classes of $K p$ and IMF, because our data base is not large enough to separate statistical effects due to IMF and to magnetic activity.

Figure 2 shows the isocontours of the field-aligned current patterns resulting from the combination of EISCAT observations below $70^{\circ}$ invariant latitude, and of their extensions at higher latitudes with Rich and Kamide's (1983) model parametrized from EISCAT auroral observations. Downward currents are represented by solid isocontours and upward currents by dashed isocontours. For $2<K p<4$ (Fig. 2a), the model extension describes, at latitudes just beyond the radar field of view, the poleward edge of the observed region 1 sheets on the nightside, and the continuation of the evening region 1 sheet by a high-latitude intrusion into the prenoon sector, overlapping the morning sheet. For $4<K p<6$ (Fig. 2b), the maximum density zones of region 1 are already observed on the nightside, and the extension mainly concerns the high-latitude dayside current system.

\section{Results}

From these polar distributions of ionospheric conductances and field-aligned currents extrapolated from EISCAT auroral statistics, we solve Eq. (1) of the convection potential within the polar cap (above $70^{\circ}$ ). The boundary conditions at $70^{\circ}$ invariant latitude are 

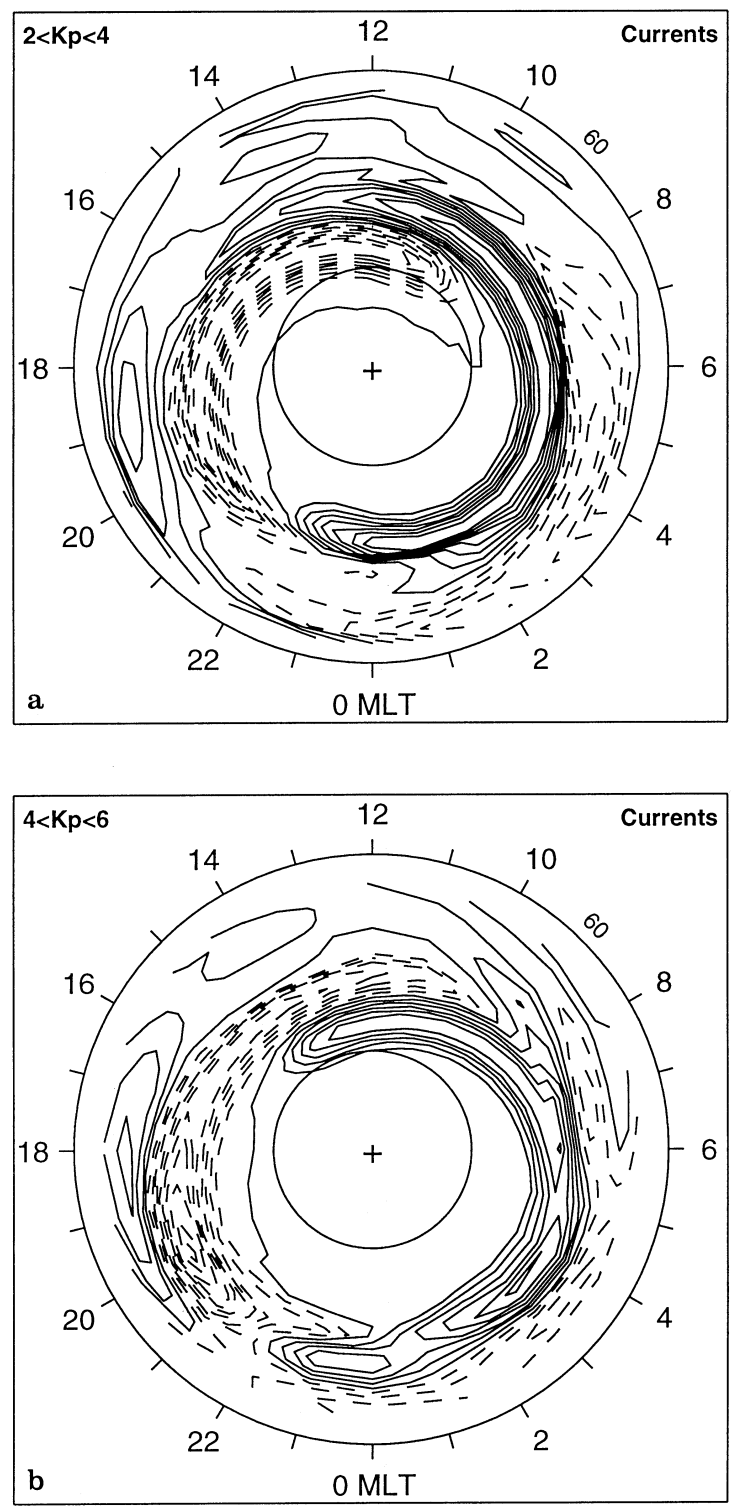

Fig. 2a,b. Isocontours of the field-aligned currents represented in polar maps similar to Fig. 1. The contour interval is $0.075 \mu \mathrm{A} / \mathrm{m}^{2}$ for a $2<K p<4$ and $\mathbf{b} 0.12 \mu \mathrm{A} / \mathrm{m}^{2}$ for $4<K p<6$

provided by the convection patterns inferred by Senior et al. (1990) from companion statistics. The polar maps in Fig. 3a,b display the equipotential lines, resulting from the combination of the EISCAT statistics below $70^{\circ}$ and of the result of Eq. (1) above $70^{\circ}$, respectively for the two considered ranges of magnetic activity $2<K p<4$ and $4<K p<6$. The bold line $(0 \mathrm{kV})$ separates positive potentials (solid lines) and negative potentials (dashed lines). Along the polar boundary $\Gamma_{p o l}$ at $89^{\circ}$ invariant latitude, the potential, assumed constant, takes a value close to 0 , respectively $-0.7 \mathrm{kV}$ and $-0.3 \mathrm{kV}$ for the two cases. The equipotential lines describe the classical twin-vortex convection pattern, with the polar antisunward flow and the sunward return at lower latitudes. As expected, the polar cap potential drop increases with magnetic activity from $38 \mathrm{kV}$ to
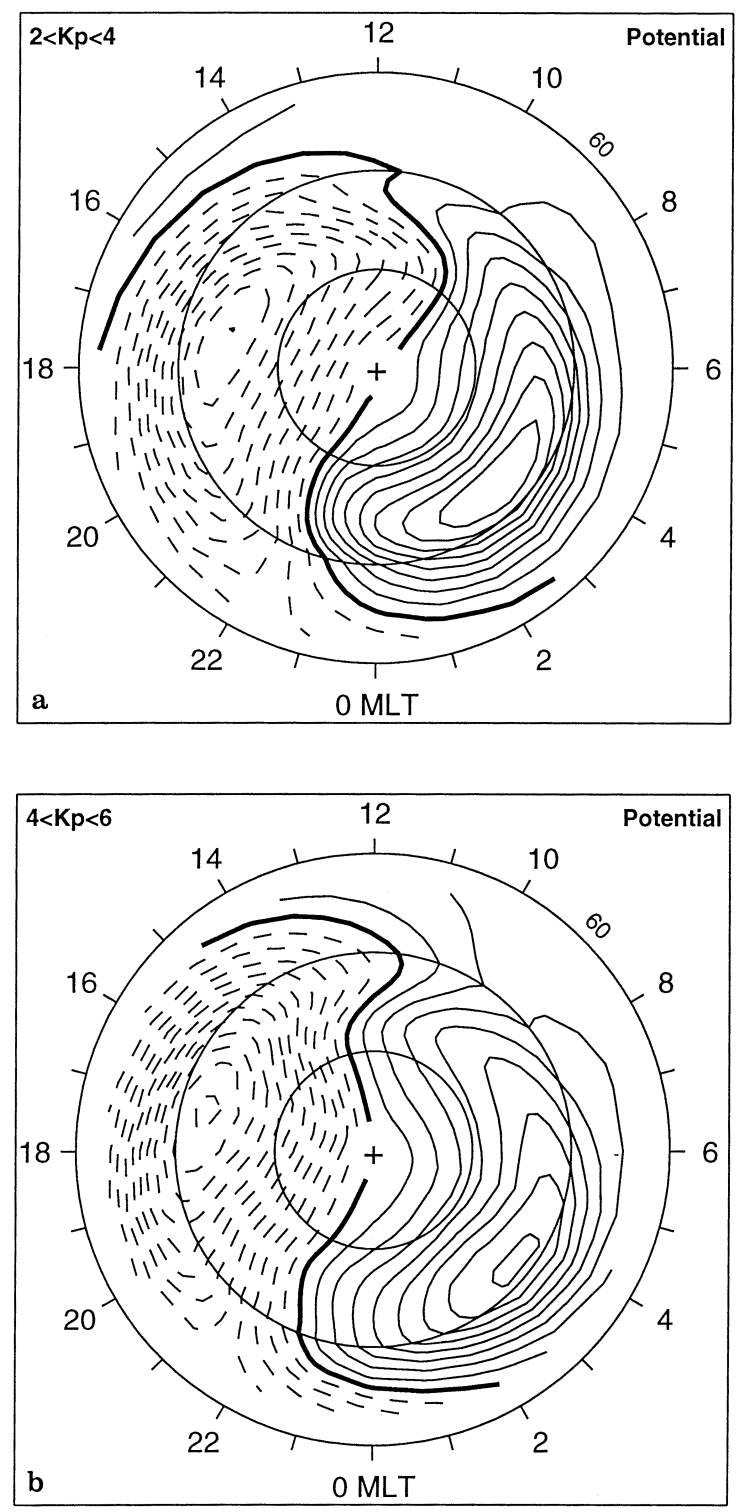

Fig. 3a, b. Equipotentials of the convection electric field represented in polar maps similar to Fig. 1. The contour interval is a $2 \mathrm{kV}$ for $2<K p<4$, and $\mathbf{b} 3 \mathrm{kV}$ for $4<K p<6$. The bold line corresponds to $0 \mathrm{kV}$

$61 \mathrm{kV}$; it approaches closely the predictions of Foster et al. (1986b), but seems slightly underestimated relative to other studies (for further details and comparisons, see Senior et al., 1990).

We discuss next the main features of the polar cap convection against previous published results. The use of various parameters and indices, IMF, $K p$, or $A E$, in the various studies does not allow a direct quantitative comparison. In fact, if their definitions and variations cannot be easily related, they involve general tendencies which may at least suggest qualitative information. As already noticed by Foster et al. (1986a), the $K p$ or $A E$ indices give an indication of the strength of ionospheric currents, a situation which is predominantly (but not only) expected for an IMF orientation favourable to the merging at the magnetopause. Consequently, in the 
absence of $K p$ dependence in previous studies, we retain as the most plausible criteria for comparison: (1) IMF $B z<0$, generally expected for active periods, (2) IMF $B y<0$ or $>0$, consistently with the choice of the fieldaligned model best fitted to EISCAT observations at auroral latitudes, and (3) spring or fall, to approach the equinox conditions, assumed for the conductance distribution.

The centres of the dawn and dusk cells, respectively located around $73^{\circ}$ and $75^{\circ}$ invariant latitude for moderate activity, move slightly equatorward $\left(72^{\circ}\right.$ and $73^{\circ}$ ) with activity, in global agreement with Foster et al. (1986a), Holt et al. (1987), and Richmond et al. (1988) in comparable situations, de la Beaujardière et al. (1991) for weak $K p$ indices, and also by Friis-Christensen et al. (1985) for IMF $B z<0$. Our results show that the local time location of the vortex centres at 17 MLT and 3-3.5 MLT depends little on the magnetic activity level at the steady state, consistently with most comparable statistics, except maybe some cases with more sunward cells predicted by Friis-Christensen et al. (1985).

For $2<K p<4$, the dusk cell spreads towards earlier prenoon times than for stronger activity, which could be interpreted as an effect of the intrusion of the region 1 upward currents to this local time sector (case 3 of Rich and Kamide, 1983 with IMF $B y<0$ ). Mainly because of the close connection of our results on $K p$-dependent auroral statistics, the role of IMF $B y$ on the structure of the polar convection, already extensively studied (see for example, Friis-Christensen et al., 1985; Heppner and Maynard, 1987), remains beyond the scope of our work. We note a good agreement with the convection patterns, which were inferred from Millstone Hill statistics in comparable situations by Foster et al. (1986a), or computed by Rich and Kamide (1983) for a similar current distribution at dayside high-latitudes, but different boundary conditions on the potential at $\Gamma_{p o l}$. This last point confirms a posteriori that the convection pattern is not very sensitive to the polar boundary condition.

Following Holt et al. (1987), the places where the flow diverges indicate the centres of the regions of flux tube entry and exit from the polar cap, and the orientation of the separation line between the two cells. For $2<K p<4$, the cell separation appears approximately aligned along the meridian 10:00-22:00 MLT. For $4<K p<6$, the polar cap flow follows a somewhat distorted path along a bent separation line: it still enters the polar cap at prenoon local times but in a direction approximately antisunward, and it then turns within the polar cap to exit around 21:00 MLT. This behaviour agrees well with Foster et al. (1986a) in conditions roughly similar $(3<K p<5$, IMF $B z<0$, IMF $B y>0$ ). More generally, the global orientation of the polar cap flow presents overall features similar to the predictions of Friis-Christensen et al. (1985) in conditions of IMF $B z<0$, and IMF $B y<0$ or IMF $B y>0$, possibly related to our moderate or disturbed activity levels. It is generally admitted that the IMF direction is controlling the respective size of the convection cells and the location of their centres. Our results also suggest that the auroral electrodynamics may contribute to distortion of the orientation of the convection flow within the polar cap and its connections to the auroral circulation (entry, exit).

Empirical models were derived from EISCAT statistics. They are based on theoretical functions which combine a Fourier analysis in MLT and an expansion in Legendre polynomials $P_{i}$ depending on invariant latitude $\Lambda$, both up to the 5th order. We apply the same procedure (Alcayde et al., 1986) to the whole potential pattern represented in Fig. 3. The theoretical expression for the potential $\phi$ is given by:

$\phi=\sum_{i=0}^{5} \sum_{j=0}^{5} P_{i}(x)\left(A_{i j} \cos (j \varphi)-B_{i j} \sin (j \varphi)\right)$

with $x$ depending on the invariant latitude $\Lambda$ as:

$x=\frac{2 \Lambda-\Lambda \max -\Lambda \min }{\Lambda \max -\Lambda \min }$

Tables 1 and 2 give the coefficients $A_{i j}$ and $B_{i j}$, for both magnetic activity ranges, with $\Lambda \max =89^{\circ}$, $\Lambda \min =62^{\circ}$ for the case $2<K p<4$ and $\Lambda \min =63^{\circ}$ for the case $4<K p<6$.

Table 1. Coefficients of the theoretical functions fitting the potential $\phi$ between $62^{\circ}$ and $89^{\circ}$ invariant latitude for $2<K p<4$

\begin{tabular}{|c|c|c|c|c|c|c|}
\hline$A i j$ & $i=0$ & $i=1$ & $i=2$ & $i=3$ & $i=4$ & $i=5$ \\
\hline$j=0$ & -0.9399 & -1.0918 & 0.0045 & 1.2456 & 1.0582 & -0.9043 \\
\hline$j=1$ & 3.1903 & 2.2052 & -5.9740 & -1.0665 & 2.0654 & 0.1739 \\
\hline$j=2$ & 1.5119 & -0.8418 & -2.4266 & 1.7585 & 0.8337 & -0.9363 \\
\hline$j=3$ & 0.4583 & 0.0282 & -0.3246 & -0.3950 & -0.0931 & 0.5597 \\
\hline$j=4$ & 0.1774 & 0.0788 & -0.3921 & -0.0442 & 0.2791 & 0.0473 \\
\hline$j=5$ & 0.0818 & -0.0133 & -0.1248 & -0.0448 & 0.1658 & 0.0219 \\
\hline$\overline{B i j}$ & $i=0$ & $i=1$ & $i=2$ & $i=3$ & $i=4$ & $i=5$ \\
\hline$\overline{j=0}$ & - & - & - & - & - & - \\
\hline$j=1$ & -8.5191 & 1.0008 & 10.7078 & -1.9007 & -3.2563 & 2.0404 \\
\hline$j=2$ & -0.9084 & 2.2221 & 0.1887 & -2.5344 & 0.6571 & 1.2201 \\
\hline$j=3$ & 0.0995 & 0.5375 & -0.4844 & -0.3770 & 0.1924 & -0.0049 \\
\hline$j=4$ & -0.1537 & 0.0146 & 0.0264 & 0.1386 & 0.0222 & -0.0886 \\
\hline$j=5$ & 0.1605 & 0.0237 & -0.1643 & -0.0665 & -0.0452 & 0.1473 \\
\hline
\end{tabular}


Table 2. Coefficients of the theoretical functions fitting the potential $\phi$ between $63^{\circ}$ and $89^{\circ}$ invariant latitude for $4<K p<6$.

\begin{tabular}{|c|c|c|c|c|c|c|}
\hline$A i j$ & $i=0$ & $i=1$ & $i=2$ & $i=3$ & $i=4$ & $i=5$ \\
\hline$j=0$ & -0.7117 & 0.5135 & -0.4616 & -0.4078 & 1.1933 & 0.0921 \\
\hline$j=1$ & 2.4267 & -0.1411 & -6.4294 & 5.3276 & 0.4396 & -2.8522 \\
\hline$j=2$ & 4.2835 & -0.6834 & -4.9546 & 1.0739 & 0.2156 & 0.3763 \\
\hline$j=3$ & -0.7007 & -0.3697 & 1.1688 & 0.0855 & -0.4737 & 0.4687 \\
\hline$j=4$ & -0.1589 & 0.1767 & 0.2449 & -0.2995 & -0.1289 & 0.2418 \\
\hline$j=5$ & -0.0037 & -0.0025 & -0.0258 & 0.1190 & -0.0982 & -0.0945 \\
\hline$B i j$ & $i=0$ & $i=1$ & $i=2$ & $i=3$ & $i=4$ & $i=5$ \\
\hline$j=0$ & - & - & - & - & - & - \\
\hline$j=1$ & -16.0086 & 7.2953 & 13.4689 & -5.0066 & -1.3693 & 2.4084 \\
\hline$j=2$ & 0.3759 & 2.4620 & -2.1952 & -1.5764 & 1.4280 & -0.1752 \\
\hline$j=3$ & 0.4866 & 0.0522 & -0.7763 & 0.3554 & -0.2402 & -0.0130 \\
\hline$j=4$ & -0.1171 & -0.4327 & 0.6129 & 0.3083 & -0.7504 & 0.4626 \\
\hline$j=5$ & 0.2846 & -0.2216 & -0.0030 & -0.0723 & -0.1377 & 0.2560 \\
\hline
\end{tabular}
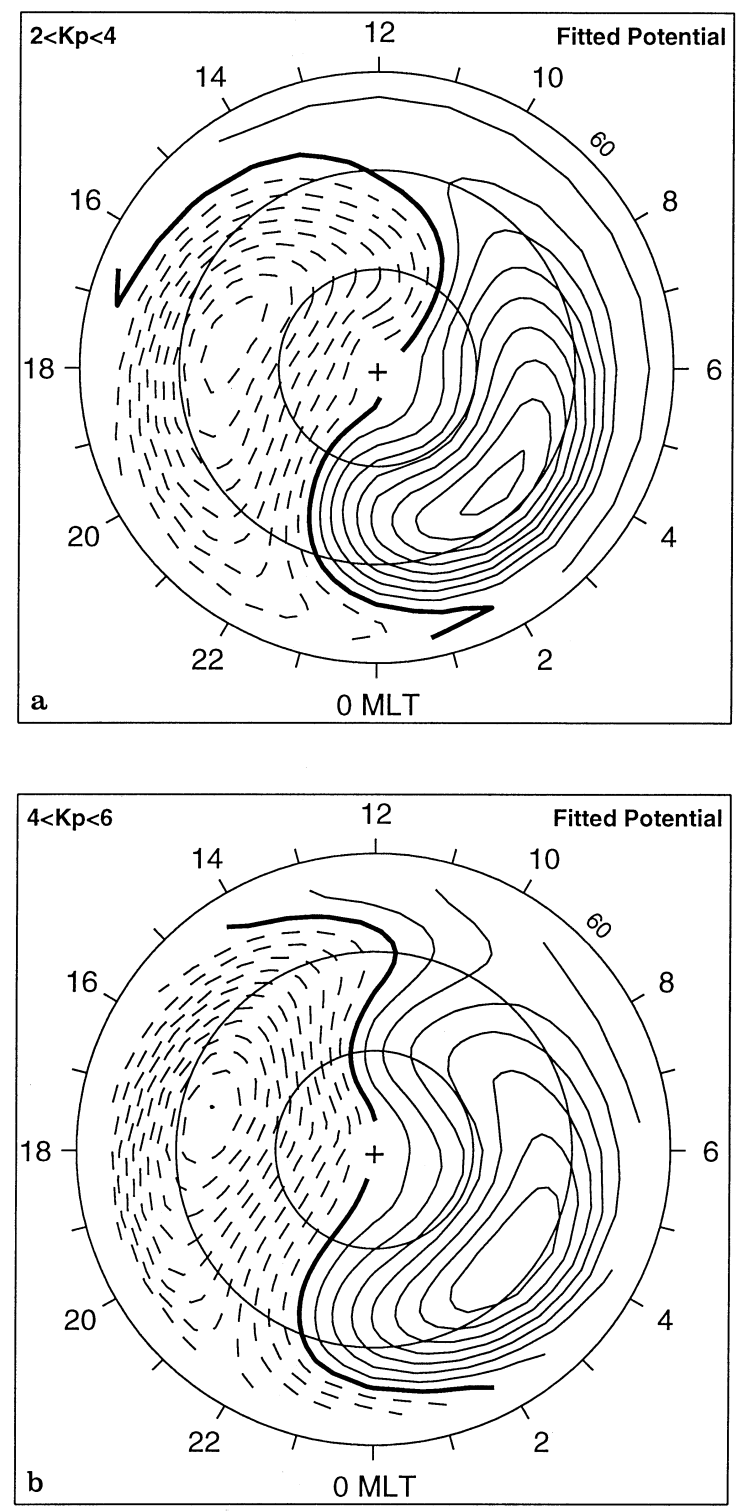

Fig. 4a, b. Analytical models for the convection potential represented in polar maps identical to Fig. 3 (see text for details)
The results are displayed in Fig. 4. Apart from the smoothing of localized irregularities at $70^{\circ}$ latitude near 10 MLT, they closely approach the convection patterns presented in Fig. 3. Finally, they propose a simple analytical representation of the large-scale convection at auroral and polar latitudes, in steady magnetic conditions.

\section{Conclusions}

Unexpected ionospheric flow structures within the polar cap, such as sunward reversals, localized shears, extra cells, departing from the classical antisunward convection, were reported mainly from satellite observations. As a first step towards the understanding of transient or localized events in the polar cap and the quantitative estimate of their signatures, this study aims at describing the convection flow pre-existing within the polar cap for steady conditions. This goal already resulted in various approaches such as the modelling from various configurations of conductances and currents (see for example, Blomberg and Marklund, 1991), the extrapolation of observations from various instruments (see for example, Foster et al., 1986a, b; Heppner and Maynard, 1987), or the combination of observations and models as in the AMIE procedure (Richmond and Kamide, 1988). Our proposal was a contribution to these investigations using specific capabilities of EISCAT observations and of numerical methods.

One advantage of the EISCAT UHF radar is the tristatic measurement of velocities, which avoids the use of additional assumptions. Secondly, the measurement by EISCAT of the scalar parameters simultaneously with the velocity vectors gives access to the auroral electrodynamics. Statistical models of convection (Senior et al., 1990), conductances (Senior, 1991) and currents (Fontaine and Peymirat, 1996) were achieved from the same data base and for the same magnetic conditions. They provide a consistent description of the auroral ionosphere, which gives a solid basis to allow us to infer polar cap convection patterns. Finally, EISCAT 
statistics are keyed to the $K p$ index, which implies the same $K p$-dependence for the results.

The numerical method that we use does not depend on any magnetic activity index nor on the time scale, and could be applied to any spatial distribution of the electrodynamic parameters in the auroral zone. It rests on the finite element technique to solve the second-order differential equation for the polar cap potential, and involves a variational formulation which directly includes the boundary conditions, similarly to Peymirat and Fontaine (1994). The advantages are the uniqueness of the computed solution and the rigorous preservation of the boundary conditions. These boundary conditions are provided by the EISCAT statistical models of convection potential at auroral latitudes. The equation also depends on the polar cap distributions of conductances, dominated by the solar illumination, and of fieldaligned currents, mainly flowing at auroral latitudes. However, part of the current system remains beyond the radar range: mainly the dayside current system, and the poleward edge of the nightside current sheets. They are extrapolated from the analytical models of Rich and Kamide (1983), but their influence is restricted by imposing on them the constraint to fit EISCAT auroral observations. The case of quiet magnetic activity is discarded because the extrapolation of the whole region 1, shrunk to a position almost poleward of EISCAT observations, could produce unrealistic patterns.

For moderate $(2<K p<4)$ and disturbed $(4<K p<6)$ activities, the polar cap potential is computed between $70^{\circ}$ and $89^{\circ}$ invariant latitude, and displayed on maps together with the corresponding statistical potential inferred from EISCAT below $70^{\circ}$ (Senior et al., 1990). It reproduces the classical two-cell pattern. The cross-polar cap potential drop increases with magnetic activity in agreement with previous studies (Foster et al., 1986a; Heppner and Maynard, 1987), but with a slight underestimation as already discussed by Senior et al. (1990). The centre of the dawn and dusk cells, located at $73^{\circ}$ and $75^{\circ}$ invariant latitudes for moderate activity, moves equatorward $\left(72^{\circ}\right.$ and $\left.73^{\circ}\right)$ with magnetic activity. On the contrary, the local time location of the cell centres does not significantly vary with activity. At dusk, it occurs around 17 MLT, while it exhibits a larger shift towards midnight (3-3.5 MLT) at dawn. This is a general trend, already noticed in comparable situations (Foster et al., 1986a; Holt et al., 1987; Richmond et al., 1988; Senior et al., 1990; de la Beaujardière et al., 1991), apart from perhaps FriisChristensen et al. (1985) where predicted patterns are globally shifted sunward.

The orientation of the convection flow over the polar cap is found to be well aligned along the meridian 10:00 22:00 MLT for moderate activities. For disturbed periods, it follows a somewhat distorted path, entering the polar cap at prenoon local times in an approximately antisunward direction, and then turning within the polar cap to exit around 21:00 MLT. Our results suggest that the auroral electrodynamics contribute to the polar cap convection pattern, in addition to the well-known effects of the IMF orientation on the cell shape and location.
Finally, EISCAT statistics and numerical results are combined to build analytical convection models for both auroral and polar regions (above $62^{\circ}$ invariant latitude) as a function of the magnetic activity level. Such predictions of the large-scale polar convection in steady conditions should provide tools to identify the largescale effects and to estimate the signature of specific events on the convection patterns observed by instruments recently deployed in the polar cap such as the EISCAT Svalbard Radar (ESR) and the SuperDARN network.

Acknowledgements. The EISCAT facility is supported by the Research Councils of Finland (SA), France (CNRS), Germany (MPG), Norway (NFR), and United Kingdom (PPARC). This work was supported by the Centre National de la Recherche Scientifique (CNRS) and by the Universite de Versailles-SaintQuentin (UVSQ).

Topical Editor, D. Alcaydé thanks T. Yeoman for his help in evaluating this paper.

\section{References}

Alcaydé D., G. Caudal, and J. Fontanari, Convection electric fields and electrostatic potential over $61^{\circ}<\Lambda<72^{\circ}$ invariant latitude observed with the European incoherent scatter facility, $J$. Geophys. Res., 91, 233-247, 1986.

Blomberg L. G., and G. T. Marklund, High-latitude convection patterns for various large-scale field-aligned current configurations, Geophys. Res. Lett., 18, 717-720, 1991.

Burke, W. J., M. C. Kelley, R. C. Sagalyn, M. Smiddy, and S. T. Lai, Polar cap electric field structures with a northward interplanetary magnetic field, Geophys. Res. Lett., 6, 21-24, 1979.

de la Beaujardière, O., D. Alcaydé, J. Fontanari, and C. Leger, Seasonal dependence of high-latitude electric fields, J. Geophys. Res., 96, 5723-5735, 1991.

Fontaine D., and C. Peymirat, Large-scale distributions of ionospheric and field-aligned currents inferred from EISCAT, in press, Ann. Geophysicae, 1996.

Foster, J. C., J. M. Holt, R. G. Musgrove, and D. S. Evans, Solar wind dependencies of high-latitude convection and precipitation, in Solar Wind-Magnetosphere Coupling, Ed. Y. Kamide, and J. A. Slavin, Terra Scientific Publishing Company, Tokyo, pp 477-494, 1986a.

Foster, J. C., J. M. Holt, R. G. Musgrove, and D. S. Evans, Ionospheric convection associated with discrete levels of particle precipitation, Geophys. Res. Lett., 13, 656-659, 1986b.

Foster, J. C., T. Fuller-Rowell, and D. S. Evans, Quantitative patterns of large-scale field aligned currents in the auroral ionosphere, J. Geophys. Res., 94, 2555-2564, 1989.

Friis-Christensen E., Y. Kamide, A. D. Richmond, and S. Matsushita, Interplanetary magnetic field control of high latitude electric fields and currents determined from Greenland magnetometer data, J. Geophys. Res., 90, 1325-1338, 1985.

Fujii, R., and T. Iijima, Control of the ionospheric conductivities on large-scale Birkeland current intensities under geomagnetic quiet conditions, J. Geophys. Res., 92, 4505-4513, 1987.

Hardy, D. A., M. S. Gussenhoven, R. Raistrick, and W. J. McNeil, Statistical and functional representations of the pattern of auroral energy flux, number flux, and conductivity, J. Geophys. Res., 92, 12275-12294, 1987.

Heppner, J. P., and N. C. Maynard, Empirical high-latitude electric field models, J. Geophys. Res., 92, 4467-4489, 1987.

Hill, T. W., Theoretical models of polar-cap convection under the influence of a northward interplanetary magnetic field, $J$. Atmos. Terr. Phys., 56, 185-194, 1994. 
Holt, J. M., R. H. Wand, J. V. Evans, and W. L. Oliver, Empirical models for the plasma convection at high-latitudes from Millstone Hill observations, J. Geophys. Res., 92, 203-212, 1987.

Iijima, T., and T. A. Potemra, The amplitude distribution of fieldaligned currents at northern high latitudes observed by TRIAD, J. Geophys. Res., 81, 2165-2174, 1976a.

Iijima, T., and T. A. Potemra, Field-aligned currents in the dayside cusp observed by TRIAD, J. Geophys. Res., 81, 5971-5979, $1976 b$.

Iijima, T., and T. A. Potemra, Large-scale characteristics of field aligned currents associated with substorms, J. Geophys. Res., 83, 599-615, 1978.

Lu, G., A. D. Richmond, B. A. Emery, P. H. Reiff, O. de la Beaujardière, F. J. Rich, W. F. Denig, H. W. Kroehl, L. R. Lyons, J. M. Ruohoniemi, E. Friis-Christensen, H. Opgenoorth, M. A. L. Persson, R. P. Lepping, A. S. Rodger, T. Hughes, A. McEwin, S. Dennis, R. Morris, G. Burns, and L. Tomlinson, Interhemispheric asymmetry of the high-latitude ionospheric convection pattern, J. Geophys. Res., 99, 6491-6510, 1994.

McDiarmid, J. B., J. R. Burrows, and M. D. Wilson, Large-scale magnetic field perturbations and particle measurements at $1400 \mathrm{~km}$ on the dayside, J. Geophys. Res., 82, 1431-1441, 1979.

Papitashvili, V. O., B. A. Belov, D.S. Faermark, Ya. I. Feldstein, S. A. Golyshev, L. I. Gromova, and A. E. Levitin, Electric potential patterns in the northern and southern polar regions parametrized by the interplanetary magnetic field, J. Geophys. Res., 99, 13251-13262, 1994.
Peymirat, C., and D. Fontaine, Numerical simulation of magnetospheric convection including the effect of field-aligned currents and electron precipitation, J. Geophys. Res., 99, 11155-11176, 1994.

Rich, F. J., and Y. Kamide, Convection electric fields and ionospheric currents derived from model field-aligned currents at high latitudes, J. Geophys. Res., 88, 271-281, 1983.

Rich, F. J., and M. Hairston, Large-scale convection patterns observed by DMSP, J. Geophys. Res., 99, 3827-3844, 1994.

Richmond, A. D., and Y. Kamide, Mapping electrodynamic features of the high-latitude ionosphere from localized observations: technique, J. Geophys., Res., 93, 5741-5759, 1988.

Richmond, A. D., Y. Kamide, B. H. Ahn, S. I. Akasofu, D. Alcaydé, M. Blanc, O. de la Beaujardière, D. S. Evans, J. C. Foster, E. Friis-Christensen, T. J. Fuller-Rowell, J. M. Holt, D. Knipp, H. W. Kroehl, R. P. Lepping, R. J. Pellinen, C. Senior, and A. N. Zaitzev, Mapping electrodynamics features of the high-latitude ionosphere from localized observations: combined incoherentscatter radar and magnetometer measurements for January 18 19, 1984, J. Geophys. Res., 93, 5760-5776, 1988.

Senior, C., D. Fontaine, G. Caudal, D. Alcaydé, and J. Fontanari, Convection electric fields and electrostatic potential over $61^{\circ}<\Lambda<72^{\circ}$ invariant latitude observed with the European incoherent scatter facility. 2. Statistical results, Ann. Geophysicae, 8, 257-272, 1990.

Senior, C., Solar and particle contributions to auroral heightintegrated conductivities from EISCAT data: a statistical study, Ann. Geophysicae, 9, 449-460, 1991. 